\title{
Communicative Approach in Teaching Students of Mining Specialties to Foreign Language Reading
}

\author{
Lyubov Fedyanina ${ }^{1,}$, Sergey Lebedintsev ${ }^{2}$, and Vyacheslav Gustov ${ }^{2}$ \\ ${ }^{1}$ Kemerovo State University, 650043, 6 Krasnaya St., Kemerovo, Russia \\ ${ }^{2}$ T.F. Gorbachev Kuzbass State Technical University, 650000, 28 Vesennyaya St., Kemerovo, Russia
}

\begin{abstract}
This article is devoted to teaching foreign-language reading intended for students studying at the mining specialties of the higher mining school. The authors share with their practical and theoretical experience as well as innovative ideas for the development and construction of a level classification of testing task forms, in order to use them effectively in mining. It is well known that the achievement of the goals and objectives of the curriculum as well as rational learning by mining students and their interest in acquiring and using mining knowledge depend on properly selected test tasks. The main component of communicative competence is considered to be a textual competence, under which is understood as a set of mining knowledge and skills. The selection of testing tasks is based on the methodological principle from simple to complex. Testing tasks at different text levels help to overcome the difficulties taking place in the course of decoding mining information.
\end{abstract}

\section{Introduction}

In Russia, under present-day conditions of global communication increasingly attention is paid to the teaching of foreign languages in general and to the innovative methodological techniques in particular. If we talk about mining education, today, one of the topical issues is the training of highly-qualified mining engineers, whose knowledge and skills should fully meet the requirements for the young professionals of a new generation.

The new model of language training at the higher mining school, which is formed in the changing Russia, should take into account the specifics of the labor market in the mining industry, the demand for the personnel in this field.

The three-stage language teaching at the higher mining school (undergraduate studies, MA course and postgraduate course), introduced in the first decade of the $21^{\text {st }}$ century, provides a student with new opportunities for the use of theoretical and practical knowledge in the mining industry, mining science and education, as well as it contributes to the disclosure of his creative potential as a person, takes into account the prospects of his career

\footnotetext{
*Corresponding author: fedianina@inbox.ru
} 
growth, competitiveness, allows to realize an international communication through the world-wide Internet.

Consequently, the exchange of international scientific and technological information is of increasing significance all over the world. Therefore, the Russian student, as a future specialist in mining, needs to master the methods of extraction and processing of foreign language information to improve his professional competence. To do this, during the period of study at the higher mining school, he should improve his foreign language professional communicative competence.

\section{Materials and Methods}

The main object of this study is to present a technology of cognitive decoding of information by using test tasks and exercises in the students' teaching of mining specialties to the foreign language reading.

To achieve these aims, a high school teacher of a foreign language should be based on the traditional methods and methodologies that are implemented and used quite effectively in the teaching of foreign languages as well as on innovative ideas (on his own developments of the task system) that have passed all the necessary stages of testing and are used in classroom and extracurricular activities of students. Thus he should form a certain set of knowledge and skills for the students to extract useful information for specific speaking tasks in such a receptive type of a speech activity as reading.

A professional-oriented text and related test tasks correspond with the aims of teaching to the foreign language reading among students studying mining and meet all the requirements of the communicative approach.

Professional-oriented texts as a kind of scientific and technical literature allow students studying mining to become familiar with the world achievements in the field of science and technology. Foreign language professional-oriented texts in the learning to read must familiarize them with phenomena, facts and scientific terminology that are understandable to students of mining specialties as well as develop their interest in their professional activities and increase the importance and level of their knowledge about a modern society.

Professional-oriented text as one of the components of the scientific style, has its own communicative orientation, i.e. it has its specificity, which implementation is carried out by a number of functions:

- to reflect reality;

- to store and accumulate knowledge;

- to receive new knowledge;

- to transmit a complete information.

It is known that the basis of acts of communication is a reflection by a man of his surrounding objective reality. This reflection should not present cognition of any separate aspects of reality. It should be relatively comprehensive and complete. To cognize reality an act of communication is a narrow discrete in nature by the specialist in a certain field of activity, unlike the layman.

Consequently, the professional-oriented text in reading is a connecting element of communication between its author and students through the use of all language means that are characteristic for the scientific functional style. Without breaking the principle of a semantic accessibility, it must explain to the recipient through a detailed description and show him the complexity of highly specialized concepts and phenomena in an accessible cognitive form.

The professional-oriented texts for reading at foreign language classes must meet certain requirements, which include: an authenticity; a professional orientation; correspondence of the content of the texts to the curriculum of the higher mining school; a 
presence of the relevant terminology; a strength of the language and a professional-oriented content of the text for a specific audience; an educational orientation; a high information content; a presence of a bright and entertaining fable of the text, an intrigue, a conflict; a variety of the text material [1: 74-76].

The basis for successful learning of the students to read the professional-oriented text are not only their individual characteristics of mental activity, the level of background knowledge, life experience, motivational orientation, but the specifics of what is being read - its functional style, form of presentation, the compositional-semantic characteristics. You need to pay attention to all these things in the selection of educational material and the preparation of textbooks for reading that meets all the requirements of professional education.

The testee in reading should be what is the final training goal, namely, the extraction of the necessary information to a certain extent in a certain situation. Therefore, while making tasks, you should determine the type of reading that will be the testee of the professionaloriented text. It should not check simultaneously several kinds of reading with using the same material of one text. The testee may be one thing but it is not a set of skills.

Also it should be taken into account the fact that reading is a receptive kind of activity, therefore, checking with the extraction of the necessary information to a certain extent in a certain situation in the text should be carried out through the reception. If some facts, ideas, concepts are the objects of control in the texts, so the tasks should be taken into account with their stylistic and functional-stylistic features. The formation of the ability to extract the maximum of possible factual, logical, linguistic, and contextual supports from the text for its better comprehension [2] plays a major role for the comprehension of the professional-oriented text, so ability to comprehend the semantic information is a necessary condition in the reading with response of the professional-oriented text.

The professional-oriented text can perform its communicative task providing the information reached the recipient / addressee:

- in corpore $-100 \%$ comprehension of the content or information of the text in the detailed reading or intensive reading;

- in the amount needed for further actions $-75 \%$ comprehension of the total content or information of the text in the skimming and up to $40 \%$ comprehension of the content or information of the text in the searching reading [3].

\section{Results and Discussion}

Pedagogical practice and research carried out in the world $[4 ; 5]$ as well as our long-term data show, that $1 / 3$ of students admitted at mining specialties of the University don't reach even the average level of learning to read in detail popular science texts at the initial stage of the foreign language teaching at the University. The reason for this is that either incorrect organization of pedagogical school control in teaching of foreign language reading, or the lack of required skills associated with the comprehension and processing of the content of the text read by students whose skills have not been formed at school. This, in its turn, would lead to students' inability: 1) to work quickly and correctly on the professional-oriented text, 2) to extract promptly the necessary information, whereupon students studying mining will not be able to use effectively these skills and abilities for their future profession after graduation from the higher mining school. The role of the teacher in this situation should be connected with the correction of the final result.

It should be noted that the success of forming or formation of skills and abilities in the detailed reading, as opposed to skimming and searching reading, is directly connected with a control of the three-level text organization $[6 ; 7]$ : 
1. A pre-textual level, which purpose is: to control the formation of skills and abilities of a mechanism of probabilistic forecasting according to the content of the text; to motivate students with information to be offered;

2. A text level - to control the formation of skills and abilities according to the meaning content of the text;

3. A post-textual level - to control a comprehension of the meaning content of the read text.

Testing tasks meet all these requirements whose degree of increasing difficulty of the performed mental task is used in reading control.

It should be noted that this formulation of the problem conforms fully to the requirements of pedagogical control of students' acquirements of assimilation levels. It is a process of transition of known actions caused by the certain situation in acquirements of the educatee.

This point corresponds to the goals and objectives of the system level approach of assimilation of acquirements where the student's activities and his experience acquired or acquiring in learning and associated with solving problems in certain situations put forward as a basis for learning. Any activities performed by a person are carried out on the basis of his previously acquired information about the ways of its implementation, which use can be either productive or reproductive.

In learning the student's performance of a certain reproductive or productive actions at any specific situation is a necessary condition for the implementation of the task aimed at assimilation of the relevant information about the implementation methods of these activities. However their application at each level of assimilation is due to a certain structural variety of components that are represented in the problem. The structural components of the task include:

- the purpose of the task;

- the situation expressed by the type of the task;

- a number of actions aimed at fulfilling of a specific task.

Implementation of the problem components occurs at the so-called digestion of knowledge per levels, reflecting the development of the student's experience in teaching to foreign language reading $[8 ; 9]$.

It is known that B. S. Bloom [10] distinguishes between 6 levels of learning experience in teaching, but in our opinion the last three ones can be united into one level that is called as creative activity. Thus, all these levels can be characterized as levels of:

- recognition,

- reproduction,

- heuristic activities,

- creative activity.

Let us consider an example of the testing task form developing according to their level classification on bases of the text "Petrographical Composition of the Coal" for students studying surveying. The purpose is a work on the professional-oriented text to form at students their skills and abilities in running control of intensive reading. Some tasks are abridged in form.

I. Testing tasks and exercises of the pre-textual level:

Petrographical Composition of the Coal

I.I. Find the following words and word combinations in your dictionary and memorize them to do vocabulary crossword test 1: a bulk, a seam, an interlayer, an algae, a bed, sclerotinitic liptobiolite, slabby-foliated coals .........

I.II. Test yourself! Do vocabulary crossword test.

I.III. Find in the text the Greek geological terms and at first try to pronounce them and then explain what they stand for into English or Russian.

I.IV. Match the verbs and word combinations. 
I.V. Try to guess and find the Russian translations of the following English words used in geology. Choose the right variant from the given element to compose the sentence.

1) The word
1) a bed
2) a bulk
3) a lamina
4) a seam stands for Russian:
A. stend.
A. kipa.
A. list.
A. shov.
B. plast.
B. gruda.
B. membrana.
B. styik.
C. krovat.
C. uchastok zemli.
C. tonkiy sloy.
C. sloy.
D. polotno
D. bolshaya chast.
D. tonkaya plastinka.
D. falts.

2) $\ldots \ldots \ldots$

I.VI. Warming up! Answer the following questions: 1) How long have you been studying surveying? 2) What do you know about the composition of the coal in the Kuznetsk Basin? 3) Do you study Petrography?

II. Testing tasks and exercises of the textual level:

II.I. Read the text "Petrographical Composition of the Coal" to answer the following questions: 1) In what region do liptobiolites occur? 2) What are humic coals are mainly built up by? 3) How do liptobiolites look like in their outward aspects? 4) .......

Petrographical Composition of the Coal

The bulk of the Kuznetsk Basin coals relate to humolites, there are also some small quantities of sapropeites and liptobiolites.

Liptobiolites occur in the Devonian seams in the Barzassky region. These coals by $40 \%$ are built up by cutinite developed from a thick plant cuticle. In their outward aspects they look like slabby-foliated coals easily splitting into flexible laminae (the Barzassky matting). Sclerotinitic liptobiolite has been revealed as an interlayer $0.8 \mathrm{~m}$ thick in the Volkovsky bed of the Kemerovsky region.

Sapropelites occur as interbeds $5-60 \mathrm{~cm}$ thick in the humic coal seams of the Mazurovskaya, Alykaevskaya suites and of the Tarbaganskaya series. They usually include humus and sapropelites and are of the cannel-boghead type with algae.

Humic coals are mainly built up by micro-components of the vitrinite and fusinite group. As a rule, the content of semivitrinite is low and that of leiptinite (chiefly sporinites) practically negligible. There are only very few samples which contain $10-15 \%$ of leiptinite. Depending upon their ratio of vitrinite and fusinite components 4 types of coals are distinguished.

II.II. Do a facet test. Choose the right variants from the given elements to compose sentences.

1) Liptobiolites occur in the a) humic coal seams of the Mazurovskaya a) suites
2) Sapropelites
b) Devonian seams in the Barzassky
b) region
as a) an interlayer $0.8 \mathrm{~m}$ thick
a) in the humic coal seams of the Tarbaganskaya series
b) interbeds $5-60 \mathrm{~cm}$ thick
b) in the Volkovsky bed of the Kemerovsky region

and they usually are a) a composition of humus and sapropelites with algae.

b) slabby-foliated coals easily splitting into flexible laminae.

II.III. Complete the following sentences:

1) There are only very few samples which contain $10-15 \%$ of

2) $\ldots \ldots \ldots$

II.IV. Replace the English words and word combinations in italics by their synonyms: 1) They usually contain black earth and sapropelites and are of the cannel-boghead type with seaweeds. 2) $\ldots . \ldots \ldots . . .3) \ldots \ldots \ldots$

II.V. Translate the fourth and the fifth paragraphs of the text for 20 minutes.

III. Testing tasks and exercises of post- textual level:

III.I. Discuss with your partner: 1) Why do the bulk of the Kuznetsk Basin coals relate to humolites? 2) ........ 
III. II. Tell about the petrographical composition of the Kuznetsk Basin coals using the chart given below.

III. III. Make up an abstract on the petrographical composition of the Kuznetsk Basin coals using information of Units .... Use expressions on page ....

\section{Conclusion}

In conclusion, the following should be mentioned: the development of a testing task system contributes to a more effective and qualitative formation of foreign-language professional communicative competence of students studying mining in the course of learning to read the professional-oriented texts; the use of testing tasks taking into account their level of classification, in our opinion, allows us to check the comprehension of the read professional-oriented text at the same time for all students of the group with the minimum amount of time that has been spent during the lesson and to reduce the time of their preparation for the tasks that will be fulfilled next.

\section{References}

1. Common European Framework of Reference for Languages: Learning, Teaching, Assessment (Language Policy Unit, Strasbourg, 2001)

2. M. Tengberg, Validation of sub-constructs in reading comprehension tests using teachers' classification of cognitive targets (Language Assessment, London, 2018)

3. H. D. Brown, Teaching by principles: and interactive approach to language (Addison Wesley Longman, New York, 2011)

4. M. A. Channa, Z. S. Nordinm, A. M. Abassi, International Journal of English Linguistics, 8:3, 47-54 (2018)

5. Reading between the lines: What the ACT reveals about college readiness in reading (Willey, London, 2006)

6. V. Škudienè, Studies about Languages, 2, $94-98$ (2002)

7. H. S. Alyousef, Reading Matrix, 5:2, 149 (2005)

8. H.-G. Albers, S. Bolton, Testen und Pruefen in der Grundstufe: Einstufungstest und Sprachstandspruefungen (Fernstudienheit, Berlin, 1995)

9. S. Bolton. Probleme der Leistungsmessung: Lernforschrittstests in der Grundstufe Fernstudienheit, Berlin, 2006)

10. B. S. Bloom, Taxonomy of Educational Objectives: The Classification of Educational Goals (David Mc Kay Co., New York, 1956) 